\title{
Longitudinal analysis of annual height increment differentiation in Scots pine (Pinus sylvestris L.) stands of different age classes
}

\author{
Bogna Zawieja ${ }^{1} \bowtie$, Katarzyna Kaźmierczak ${ }^{2}$ \\ ${ }^{1}$ Poznań University of Life Sciences, Faculty of Agronomy and Bioengineering, Department of Mathematical and \\ Statistical Methods,Wojska Polskiego 28, 60-637 Poznań, Poland, phone: 4861 8487153, e-mail: bogna13@up.poznan.pl \\ ${ }^{2}$ Poznań University of Life Sciences, Faculty of Forestry, Department of Forest Management, Wojska Polskiego 28, \\ 60-637 Poznań, Poland
}

\begin{abstract}
In the study, the measurements of Scots pine height increments were used to compare the increments of pine trees of different age classes. All of the analyzed trees were growing in stands located on fresh mixed coniferous forest sites. The study concerned a 10 -year period of growth of 8 tree age classes. Due to variation in climate conditions, all trees were studied over the same calendar period. Longitudinal analysis was used to compare different age classes of trees with reference to the increments in height. This procedure had not been previously used for such purpose. The results obtained did not confirm the hypothesis of parallel profiles implying that there existed differences in the growth of trees in various age groups.
\end{abstract}

\section{KeY WORDS}

age group, forests productivity, profile analysis, longitudinal data

\section{INTRODUCTION}

Knowledge about relationships between the age of trees and their height increments is very important in management of a forest system. Moreover, periodical height increments of trees are regarded as the major dendrometric characteristic with direct influence on the accuracy of determination of tree and stand volume increments. The magnitude of tree height increments is needed when using methods to determine stand productivity. The height increment is a variable characteristic and depends on several factors. The most important of these are tree age and biosocial position occupied by the tree, as well as soil and climatic or meteorological conditions (Beker 1997; Kaźmierczak 2005; Zielski 1997).

The regularity of the process of growing is independent from tree species (Assmann 1970). Differences among species are connected with the extent and length of tree natural growth phases. In the first years of a tree life - the youth or juvenile phase - the increment in height is not large. The next (second) period is called the height season or strength phase or vigor phase. During this time trees display the largest annual height increments, and the culmination point - the year 
with the largest height increment - is observed. After a few years of large height increments, trees pass into the senescent phase: the period of stabilized increments, often much smaller than those produced in the second phase (or else with same size as before).

The aim of this study was to analyze differentiation of annual height increments conditional on the age of trees. For this purpose, the statistical method of analysis of longitudinal data (also known under the name of profile analysis or longitudinal analysis) was used (multivariate analysis for repeated measurement). Generally, the height increments in trees can be divided into the categories reliant on tree age. In the literature, there are available examples on the use of the data on trees in profile analysis. In the paper by Mehtätalo (2005), the longitudinal analysis was taken into account by estimating the models as random effects models using two nested levels: stand and measurement occasion level. Lukas and Diggle (1997) used the longitudinal analysis of repeated measurements to investigate relative differences in the growth of Sitka spruce and Norway spruce seedlings during summer exposure to ozone over three growing seasons. In the study by Lappi (1997), the longitudinal analysis was used in the simultaneous statistical analysis of the height curves.

\section{Materials}

The experimental material included selected Scots pine stems from eight stands. The trees were of different age $(24,33,55,62,72,84$, and 92). The Draudt method was used as the selection method. In each age group, 25 trees were measured. Next, for each tree, ten measurements of increments were carried out over a ten-year growth period. This way, at 24 years of age, the first measurement actually applied to 15 -year-old trees whereas at 33 years of age - the first measurement applied to 24 years of age, etc. All of the stands observed were located on fresh mixed coniferous forest sites within the area of the Experimental Forest District Zielonka (temperate climate, E $17^{\circ}$ 6' 48.996", $\mathrm{N} 52^{\circ} 33^{\prime} 13.752$ ). The same calendar growth period, extending from 1989 to 1999, was taken on for each studied tree, with the purpose to eliminate the effects of additional factors (e.g. climate and weather conditions) on the height increment.

\section{Methods}

The height was measured annually - always in the same trees, and thus the record values cannot be regarded as independent random variables, since the measurements were carried out on same experimental units. Longitudinal analysis was carried out with repeated measurements (performed on the same treatment at intervals) used to analyze growth variability. The applied model is: $\mathbf{Y}=\mathbf{X} \Xi+\mathbf{e}$, where $\mathbf{Y}(k \times p)$ is the observation matrix. The columns of matrix $\mathbf{Y}$ are: $\mathbf{y}_{i j}^{\prime}=\left[y_{i j 1}, \ldots, y_{i j p}\right]$ for observation (trees) $i=1,2, \ldots, n$ and group (age) $j=1,2, \ldots, k$, where $p$ is the number of time points $(l=1,2, \ldots, p)$. Then $\mathbf{X}$ is the $(n k \times k)$ design matrix, $\boldsymbol{\Xi}$ is the $(k \times p)$ matrix of unknown parameters and $\mathbf{e}$ is the $(n k \times p)$ error matrix built from the measurement errors $e_{i j 1}$. In the above model it is assumed that $\mathbf{e}_{i j}^{\prime}=\left[e_{i j 1}, \ldots\right.$, $e_{i j p}$ ] are independent, and have the multivariate normal distribution with expectation equal zero and unknown nonsingular, full column rank, covariance matrix $\Sigma$, which is identical for each $i=1,2, \ldots, n, j=1,2, \ldots, k$.

Three hypotheses were tested in this analysis. The first was the hypothesis $H_{01}$ which assumed the absence of interactions between calendar years and stand age, i.e. parallelism of the profile of height growth for trees in different age groups. If there is no basis to reject the null hypothesis (growths of height in the studied period were independent of tree age), then the hypothesis $H_{02}$ assuming equality of the growths (profiles) is checked, as well as the hypothesis $H_{03}$ asserting the absence of changes in the time of medium growth for stands (in other words: absence of a trend, equal growths in every year of the studied period, absence of differences between years). For verification of the first and the third hypothesis, Roy's largest root is generally used, while the second hypothesis is tested using the Hotelling $T^{2}$ statistic (Morison 1990). If the hypothesis $H_{01}$ is rejected, Roy's (or Scheff's) simultaneous confidence intervals can be used to find the age groups of trees which contributed to this. Equality of the expectation for different study years should be tested in the same way. In this case $T^{2}$ statistics for dependent variables are used separately for each group. If the hypothesis $H_{01}$ is not rejected but $H_{02}$ and/or $H_{03}$ are, then Scheff's intervals can be used to find the relevant differences between groups and time points. The details of the method used were described by Zawieja 
(2012), however, in the present study, the increments of trees in the same age group were checked among different Kraft classes. All the conclusions were based at a significance level $p=0.05$.

\section{RESULTS}

Before attempting the analysis, it is worth to present general trends (profiles) of groups' means with respect to the time points. In figure 1, there are presented the profiles for the tree age groups studied. The increments of the youngest trees are most changing in the years, while the increments of the oldest tress are most stable. It should be noted, however, that increments of all age groups have a similar pattern, but the youngest tree, 24 and 33, strongly react to weather conditions (for example 1993, when precipitation was three times higher than in other years - the increments were smaller). Thus, it is reasonable to examine the hypothesis concerning parallelism of the profiles of individual groups.

Based on profile analysis, it was found that the hypothesis $H_{01}$ (profile parallelism) ought to be rejected, the Roy's statistic: $\theta=2.10997$, the critical value: $\theta_{\text {tab }}=0.152$ with parameters $S=7, M=0.5, N=80.5$ (Zawieja 2012). Rejection of the aforementioned hypothesis entailed rejection of the hypothesis of profile equality as well as that of equality of time-points effects.

Because the hypothesis of parallelism of profiles was rejected, it was necessary to check which age groups contributed to this non-parallelism of profiles. On the basis of the Scheff's confidence intervals it was concluded that the height increments of the youngest (24) and the oldest (92) trees were clearly different from other groups. The trees in age groups from 55 to 84 formed the largest homogeneous group (tab. 1).

Table 1. Multivariate comparison of multiple groups of trees (stands) at significance level $p=0.05$

\begin{tabular}{|c|c|c|c|c|c|c|c|c|}
\hline Age group & 24 & 33 & 43 & 55 & 62 & 72 & 84 & 92 \\
\hline \multirow{2}{*}{$\begin{array}{l}\text { Homogeneous } \\
\text { groups }\end{array}$} & & $\mathrm{a}$ & $\mathrm{a}$ & & & & & \\
\cline { 2 - 9 } & & & $\mathrm{b}$ & $\mathrm{b}$ & & & & \\
\cline { 2 - 9 } & & & & $\mathrm{c}$ & $\mathrm{c}$ & $\mathrm{c}$ & $\mathrm{c}$ & \\
\hline
\end{tabular}

The hypothesis of equality of time-points $H_{03}$ was rejected, thus calendar years were compared to indicate the year or years in which the increments of all groups differed significantly. In this case the pairs of consecutive years (the first year with the second, second with the third, etc.) were compared. No significant differences between 1995 and 1996 and also between 1996 and 1997 were shown (tab. 2).

Since the hypothesis of the equality of profiles was rejected, ten one-dimensional analyzes of variance were performed separately for each study year. The following values of $F$ were obtained (in subsequent groups, from the youngest to oldest) $100.58,78.84,202.72,181.56$, $59.80,117.29,81.36,49.66,46.45,40.62$ with seven degrees of freedom for the nominator and from 164 to 167 (because the outliers were removed) for the denomina-

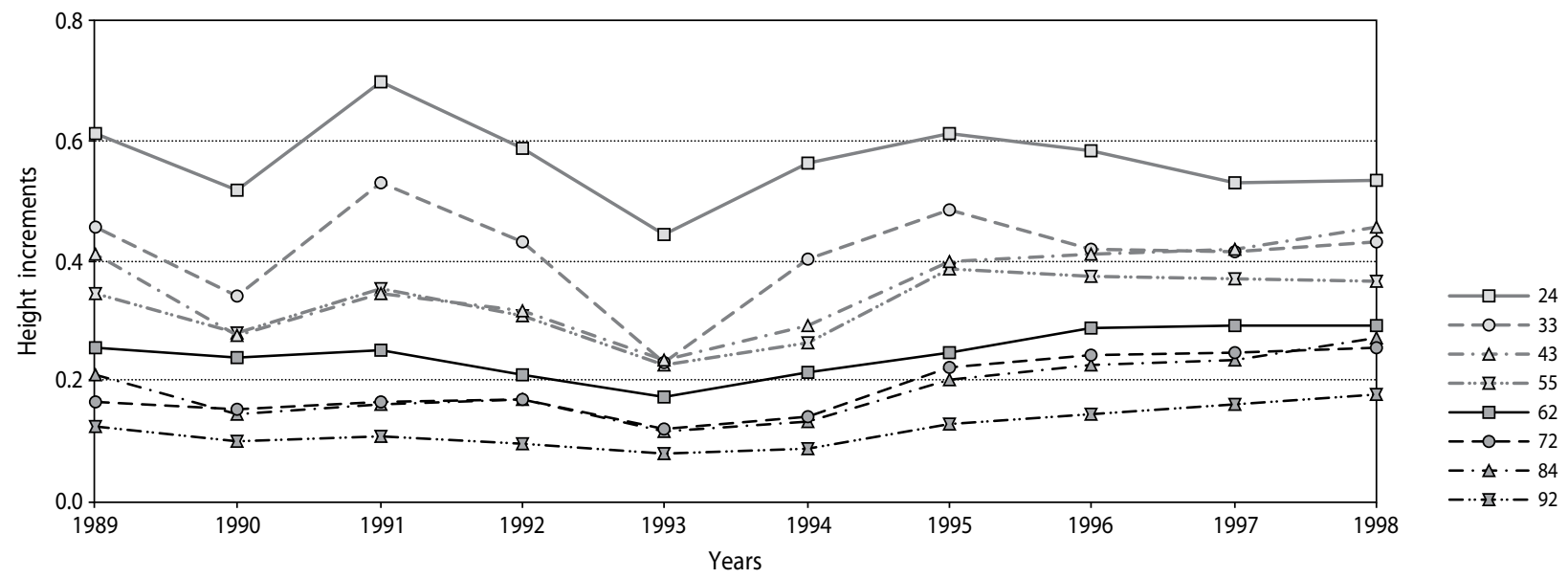

Figure 1. Mean Scots pine height increments in observation years and profiles of age-group trees in ten-year period 
tor, $p$-values were always less than 0.0001 . In all of the analyzes, the hypotheses of equality of tree age groups was rejected. Hence, the simultaneous multiple comparisons were performed. The results of the comparisons are shown in table 3 and it should be noted that the height increments in the group of the youngest trees differed from the increments in other age groups (from the age 15 to 22). In 1997, when the trees reached the age of 23 years, they did not differ from the trees from the age groups 43 and 33. The remaining age groups of trees were combined into larger or smaller homogeneous groups with reference to the height increments. The trees from the age groups: 55 and 43 years old, moreover - those from 62, 72 and 84 years and also 72,84 and 92 years formed a homogeneous group in almost every study year (with the sole exception in 1991 for the age groups: 62,72 and 84 years).

Table 2. Comparisons (contrasts) between successive calendar years of measurement (time points)

\begin{tabular}{|c|c|c|}
\hline $\begin{array}{c}\text { Study year } \\
\text { (time point) }\end{array}$ & $F$-test & $\begin{array}{c}\text { Significant difference } \\
(p \text {-value })\end{array}$ \\
\hline $1989-1990$ & 121.4 & $<0.0001$ \\
\hline $1990-1991$ & 158.3 & $<0.0001$ \\
\hline $1991-1992$ & 56.6 & $<0.0001$ \\
\hline $1992-1993$ & 236.6 & $<0.0001$ \\
\hline $1993-1994$ & 107.12 & $<0.0001$ \\
\hline $1994-1995$ & 162.0 & $<0.0001$ \\
\hline $1995-1996$ & 0.21 & 0.6512 \\
\hline $1996-1997$ & 0.06 & 0.8040 \\
\hline $1997-1998$ & 4.76 & 0.0305 \\
\hline
\end{tabular}

Table 4. Comparisons (contrasts) of successive years of measurement in individual stands (tree age groups)

\begin{tabular}{|c|c|c|c|c|c|c|}
\hline Age-group & 24 & 33 & 43 & 55 & 72 & 84 \\
\hline $1989-1990$ & - & $* * * *$ & $* * * *$ & - & - & - \\
\hline $1990-1991$ & $* * * *$ & $* * * *$ & - & $* * * *$ & - & - \\
\hline $1991-1992$ & $* * * *$ & - & - & - & - & - \\
\hline $1992-1993$ & - & $* * * *$ & & $* * * *$ & - & - \\
\hline $1993-1994$ & - & $* * * *$ & - & - & - & - \\
\hline $1994-1995$ & - & - & - & $* * * *$ & $* * * *$ & $* * * *$ \\
\hline
\end{tabular}

$* * * *$ significant differences at $p=0.00001 ;-$ no significant differences.

The tree age groups were highly different from each other as shown above. From here, separately for each of the age group, profile analyses were performed. Consequently the value of $T^{2}$ statistics exceeded the critical values (value of $T^{2}$ statistics for subsequent groups, from the youngest to oldest, were following as follows: $460.17,263.68,318.45,315.67,160.53,340.98,176.68$, 207.31, the critical value of $T_{0.05 ; 9.15}^{2}=5.853$; all $p$-values were $<0.0001)$ for every stand, so in each group the null hypothesis of absence of differences between the years was rejected. Scheff's confidence intervals were used for comparisons between increments in the successive study years (for each contrast). The results of the comparisons are given in table 4 (only for these age groups and pairs of years when significant differences existed). In the age groups: 62 and 92 years, significant differences between successive years was not detected. The height increments frequently differed between the years 1990 and 1991 (age group: 24, 33, 55 years), similarly in 1994 and 1995 (age group: 55, 72, 84 years). For the respective age groups,

Table 3. Homogeneous groups of stands (tree age determined in the year of measurement) in successive calendar years of measurement $(p=0.05)$

\begin{tabular}{|c|c|c|c|c|c|c|c|c|c|}
\hline 1989 & 1990 & 1991 & 1992 & 1993 & 1994 & 1995 & 1996 & 1997 & 1998 \\
\hline 15 & 16 & 17 & 18 & 19 & 20 & 21 & 22 & $23 \mathrm{a}$ & $24 \mathrm{a}$ \\
\hline $24 \mathrm{a}$ & $25 \mathrm{a}$ & 26 & 27 & $38 \mathrm{a}$ & 29 & $30 \mathrm{a}$ & $31 \mathrm{a}$ & $42 \mathrm{ab}$ & $43 \mathrm{ab}$ \\
\hline $34 \mathrm{ab}$ & $47 \mathrm{ab}$ & $48 \mathrm{a}$ & $49 \mathrm{a}$ & $28 \mathrm{a}$ & $39 \mathrm{a}$ & $40 \mathrm{a}$ & $41 \mathrm{a}$ & $32 \mathrm{ab}$ & $33 \mathrm{ab}$ \\
\hline $46 \mathrm{~b}$ & $35 \mathrm{~b}$ & $36 \mathrm{a}$ & $37 \mathrm{a}$ & $50 \mathrm{a}$ & $51 \mathrm{ab}$ & $52 \mathrm{a}$ & $53 \mathrm{ab}$ & $54 \mathrm{bc}$ & $55 \mathrm{bc}$ \\
\hline $53 \mathrm{c}$ & $54 \mathrm{bc}$ & 55 & $56 \mathrm{~b}$ & $57 \mathrm{ab}$ & $58 \mathrm{bc}$ & $59 \mathrm{~b}$ & $60 \mathrm{bc}$ & $61 \mathrm{~cd}$ & $62 \mathrm{~cd}$ \\
\hline $75 \mathrm{~cd}$ & $64 \mathrm{~cd}$ & $65 \mathrm{~b}$ & $78 \mathrm{bc}$ & $67 \mathrm{~b}$ & $68 \mathrm{~cd}$ & $69 \mathrm{bc}$ & $70 \mathrm{bcd}$ & $71 \mathrm{de}$ & $84 \mathrm{~cd}$ \\
\hline $63 \mathrm{~cd}$ & $76 \mathrm{~cd}$ & $77 \mathrm{~b}$ & $66 \mathrm{bc}$ & $79 \mathrm{~b}$ & $80 \mathrm{~cd}$ & $81 \mathrm{bc}$ & $82 \mathrm{~cd}$ & $83 \mathrm{de}$ & $72 \mathrm{~d}$ \\
\hline $83 \mathrm{~d}$ & $84 \mathrm{~d}$ & $85 \mathrm{~b}$ & $86 \mathrm{c}$ & $87 \mathrm{~b}$ & $88 \mathrm{~d}$ & $89 \mathrm{c}$ & $90 \mathrm{~d}$ & $91 \mathrm{e}$ & $92 \mathrm{~d}$ \\
\hline
\end{tabular}


there were found clear differences in the average increment size between the years, which is presented in figure 1. Similarly, significant differences in the increments of the age group 33, between the pairs of years: 1989 and 1990, 1990 and 1991, 1992 and 1993 as well as 1993 and 1994 can be seen in figure 1 showing average increments.

\section{Discussion}

In the present study, profile analysis method was used to determine differentiation of the height increments depending on Scots pine age classes. This is a new approach to analyzing this problem. For example, in the paper by Crecente-Campoa et al. (2010), an individual-tree growth model was developed. Stankova and DiéguezAranda (2013) presented modeling height increments based on other characteristics of trees. Gerelbaatar and Baatarbileg (2011) studied height increment changes in close correlation with diameter increment for different vegetation zones. Profile analysis do not give a model of growth but on the basis of this analysis it can be seen if the increments in the different groups of trees are the same or not in the successive years. If the increments are not the same, it can be concluded which groups differ from each other. As mentioned above, the results of profile analysis provide information as that obtained in the analysis of growth. Namely, one can conclude at which age the increments of trees do not change from year to year. In the analysis of growth, there is often observed autocorrelation. In profile analysis the effects of autocorrelation and weather conditions are excluded, in view of the fact that the analysis is tailored to data concerning repeated measurement on same experimental units. The used method of analysis for repeated measures seems to be a very good method for evaluating the increments of tree heights, and what is more, it can be used for other than Scots pine tree species as well.

\section{Conclusions}

Calculations were performed by means of profile analysis allowed to draw the following conclusions:

- The height increment of trees representing stands of the age groups 24 and 92 is different from the height increment of trees from other age groups.
- Additionally, it was clear that the youngest trees (24-year-old) finished the vigor phase of their height increment at the age of 22 years and then they passed into a less intensive growth stage.

- The results obtained indicate that in the year 1991, the homogeneous groups in terms of tree height increments differed from those observed in adjoining years.

- In the year 1991 there are only two homogenous groups of younger and older trees, missing intermediate groups linking these two groups (see tab. 3). This suggests that the conditions in that year were different than in adjoining years. Because the cause of it is not visible (weather conditions do not differ noticeably from other years, as it visible in 1993 - heavy precipitations) thus this problem will be investigated in further research.

\section{References}

Assmann E. 1970. Take principles of forest yeald study. Pergamon, Oxford, NewYork.

Beker C. 1997. Dendrometryczna charakterystyka wybranych drzewostanów sosnowych znajdujących się pod wpływem emisji przemysłowych. [Dendrometrical characteristics of Scots pine in the area under the influence of industrial air pollution]. Wyd. SGGW, Warszawa [in Polish].

Crecente-Campoa F., Soaresb P., Toméb M., DiéguezArandaa U. 2010. Modeling annual individual-tree growth and mortality of Scots pine with data obtained at irregular measurement intervals and containing missing observations. Forest Ecology and Management, 260, 1965-1974.

Gerelbaatar S., Baatarbileg N. 2011. Growth of Scotch Pine (Pinus sylvestris L.) Plantation in Northern Mongolia. Journal of Agricultural Science and Technology, B1, 1205-1210.

Kaźmierczak K. 2005. Przyrost wysokości i dokładność różnych metod jego określania na przykładzie wybranych drzewostanów sosnowych. [The height increment and accuracy of different methods of its calculation in selected Scots pine stands]. Roczniki AR Poznań, Rozprawy Naukowe, 365 [in Polish].

Lappi J. 1997. A longitudinal analysis of height/diameter curves. Forest Science, 4, 555-570. 
Lukas P., Diggle P. 1997. The use of longitudinal data analysis to study the Multi - season growth responses of Norway and Sitka spruce to summer exposure to ozone: implications for the determination of critical levels. New Phytologist, 137, 315-323.

Mehtätalo L. 2005. Height - diameter models for Scott pine and birch in Finland. Silva Fennica, 39, 55-66.

Morison D.F. 1990. Wielowymiarowa analiza statystyczna. [Multivariate statistical methods]. PWN, Warszawa [in Polish].

Stankova T.V., Diéguez-Aranda U. 2013. Height-diameter relationships for Scots pine plantations in Bulgaria: optimal combination of model type and application. Annals of Forest Research, 56 (1), 149-163.

Zawieja B. 2012. Application of the longitudinal analysis to the analysis of height increment of pine stands - simulated data. Biometrical Letters, 49 (2), 121-134.

Zielski A. 1997. Uwarunkowania środowiskowe przyrostów radialnych sosny zwyczajnej (Pinus sylvestris L.) w Polsce Północnej na podstawie wielowiekowej chronologii [Environmental conditions of radial growth of Pinus sylvestris from North Poland on the basis of long time chronology]. Wydawnictwa UMK, Toruń. 